\title{
Assessment of energy loss in aortic stenosis using Bayesian multipoint phase-contrast MRI
}

\author{
Christian Binter $^{1 *}$, Robert Manka ${ }^{1,2}$, Simon H Sündermann ${ }^{3}$, Verena Knobloch ${ }^{1}$, Matthias Stuber ${ }^{4}$, \\ Sebastian Kozerke ${ }^{1,5}$ \\ From 16th Annual SCMR Scientific Sessions \\ San Francisco, CA, USA. 31 January - 3 February 2013
}

\section{Background}

Aortic stenosis is the most prevalent valvular heart disease. The current gold standard for determination of the disease severity is Doppler echocardiography, but the decision for valve replacement is mostly based on the patient experiencing symptoms [1]. Doppler echocardiography measures the velocity across the valve, which is only indirectly linked to the energy loss associated with a diseased valve. It has recently been proposed that energy loss can be quantified directly by employing Bayesian multipoint phase-contrast MRI (PC-MRI) [2]. In this work we present preliminary data acquired in patients with severe aortic stenosis.

\section{Methods}

A Bayesian multipoint velocity encoding sequence [3] was implemented on a 3T system (Philips Healthcare, Best, The Netherlands). A navigated and cardiac-triggered 3D gradient echo sequence with spatial and temporal resolution of $2.5 \times 2.5 \times 2.5 \mathrm{~mm}^{3}$ and $36 \mathrm{~ms}$ was used. A total of 10 velocity encoding points was acquired resulting in approximately $8 \mathrm{~min}$ scan time excluding navigator efficiency. Approval of the local Ethics Review Board was obtained and patients were recruited upon informed consent. Energy loss was computed based on the ratio of turbulent to mean kinetic energy taking reflow into account as proposed previously [2]. The pressure gradients were computed analogous to Doppler echocardiography using the modified Bernoulli equation: $\mathrm{PG}=4 \mathrm{v}_{\max }{ }^{2}$.

\section{Results}

Preliminary data from two patients with symptomatic severe aortic stenosis referred for aortic valve replacement are presented. Peak velocities and turbulent kinetic energy

\footnotetext{
${ }^{1}$ Institute for Biomedical Engineering, University and ETH Zurich, Zürich, Switzerland

Full list of author information is available at the end of the article
}

(TKE) and energy loss indices (ELI) are listed in Table 1. Compared to our previous data obtained in healthy subjects [3], peak TKE in the patients presented here was found to be significantly increased $\left(149 \pm 12 \mathrm{~J} / \mathrm{m}^{3}\right.$ vs. 1350 and $1630 \mathrm{~J} / \mathrm{m}^{3}$, respectively). It is noteworthy that the patient with higher TKE values had a lower energy loss index. Values from Doppler echocardiography are given for comparison. Figure 1 shows maps of TKE in the aortic arch in both patients along with flow patterns derived from the velocity data.

\section{Conclusions}

Bayesian multipoint PC-MRI permits concurrent mapping of both mean kinetic and turbulent kinetic energy in patients and allows the assessment of relative energy loss and pressure gradients associated with aortic valve stenosis. The energy loss index was found to be approximately 8 -fold higher as compared to healthy subjects [2] and may hold promise to serve as a novel marker for grading valve disease.

Table 1 Flow parameters for both patients as determined by MRI and Doppler echocardiography.

\begin{tabular}{ccc}
\hline & Patient 1 & Patient 2 \\
\hline \multicolumn{3}{c}{ Bayesian multipoint PC-MRI } \\
\hline Peak velocities & $3.9 \mathrm{~m} / \mathrm{s}$ & $4.5 \mathrm{~m} / \mathrm{s}$ \\
Peak TKE & $1350 \mathrm{~J} / \mathrm{m}^{3}$ & $1630 \mathrm{~J} / \mathrm{m}^{3}$ \\
Peak total TKE & $12.1 \mathrm{~mJ}$ & $15.3 \mathrm{~mJ}$ \\
Energy loss index & $22.9 \%$ & $21.9 \%$ \\
Stroke volume & $56 \mathrm{ml}$ & $63 \mathrm{ml}$ \\
Mean pressure gradient & $45 \mathrm{mmHg}$ & $41 \mathrm{mmHg}$ \\
\hline \multicolumn{3}{c}{ Doppler echocardiography } \\
\hline Aortic valve area & $0.8 \mathrm{~cm}{ }^{2}$ \\
Mean pressure gradient & $48 \mathrm{mmHg}$ & $0.8 \mathrm{~cm}^{2}$ \\
\hline
\end{tabular}



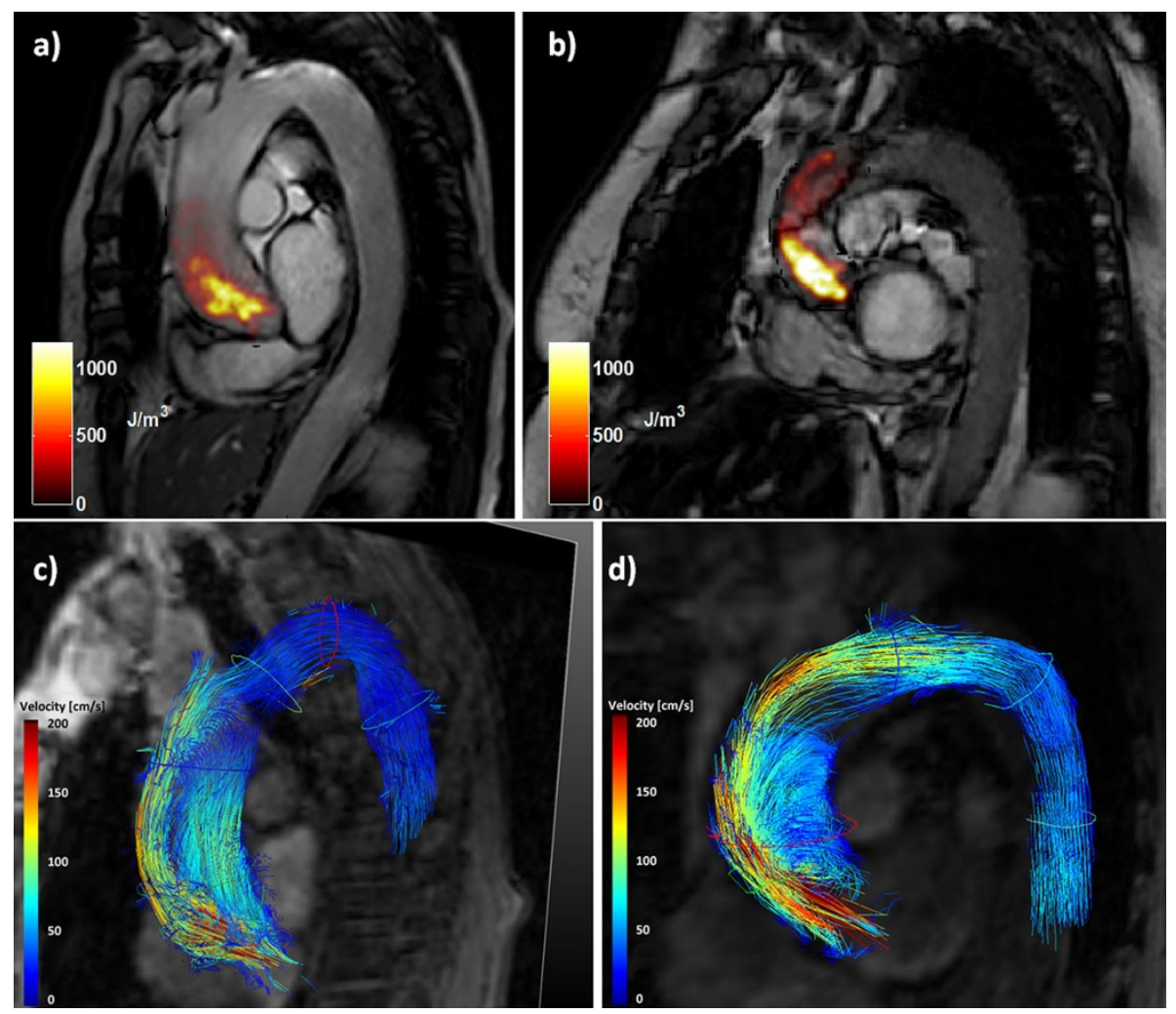

Figure 1 Maps of turbulent kinetic energy during systole in patient 1 (a) and patient 2 (b). Systolic flow pattern visualization using pathlines in patient 1 (c) and patient 2 (d). In both cases the majority of forward flow is directed along the outer wall of the aortic arch, and considerable recirculation in the ascending aorta occurs.

\section{Funding}

Christian Binter was supported by the National Competence Center in Biomedical Imaging Switzerland.

\section{Author details \\ ${ }^{1}$ Institute for Biomedical Engineering, University and ETH Zurich, Zürich, Switzerland. ${ }^{2}$ Dept. of Cardiology, University Hospital Zurich, Zurich, Switzerland. ${ }^{3}$ Division of Cardiovascular Surgery, University Hospital Zurich, Zurich, Switzerland. ${ }^{4}$ Center for Biomedical Imaging (CIBM), University of Lausanne, Lausanne, Switzerland. ${ }^{5}$ Imaging Sciences and Biomedical Engineering, King's College London, London, UK.}

Published: 30 January 2013

\section{References}

1. Carabello, et al:. Lancet 2009, 373:956-966.

2. Binter, et al.. Proc. ISMRM 2012, 20:706.

3. Binter, et al.: MRM 2012.

doi:10.1186/1532-429X-15-S1-P47

Cite this article as: Binter et al:: Assessment of energy loss in aortic stenosis using Bayesian multipoint phase-contrast MRI. Journal of Cardiovascular Magnetic Resonance 2013 15(Suppl 1):P47.

\section{Submit your next manuscript to BioMed Central and take full advantage of:}

- Convenient online submission

- Thorough peer review

- No space constraints or color figure charges

- Immediate publication on acceptance

- Inclusion in PubMed, CAS, Scopus and Google Scholar

- Research which is freely available for redistribution 